\title{
Meso/micro-texture analysis of the landslide-dam outburst sediments in the Upper Jinsha River, SE Tibetan Plateau
}

\author{
Jian Chen ${ }^{a *}$, Zhijiu Cuib, Chao Liü, Wendy Zhou ${ }^{\mathrm{d}}$ and Ruichen Chen ${ }^{\mathrm{a}}$ \\ a China University of Geosciences Beijing, School of Engineering and Technology, Beijing 100083, China; \\ (*corresponding author: tel.: +86 10 82321196; jianchen@cugb.edu.cn) \\ b Peking University, College of Urban and Environmental Sciences, Beijing 100871, China \\ c University of Alberta, Department of Civil and Environmental Engineering, Edmonton, Alberta T6G 2R3, Canada \\ d Colorado School of Mines, Department of Geology and Geological Engineering, Colorado 80401, USA
}

doi: $10.4154 / g c .2019 .29$

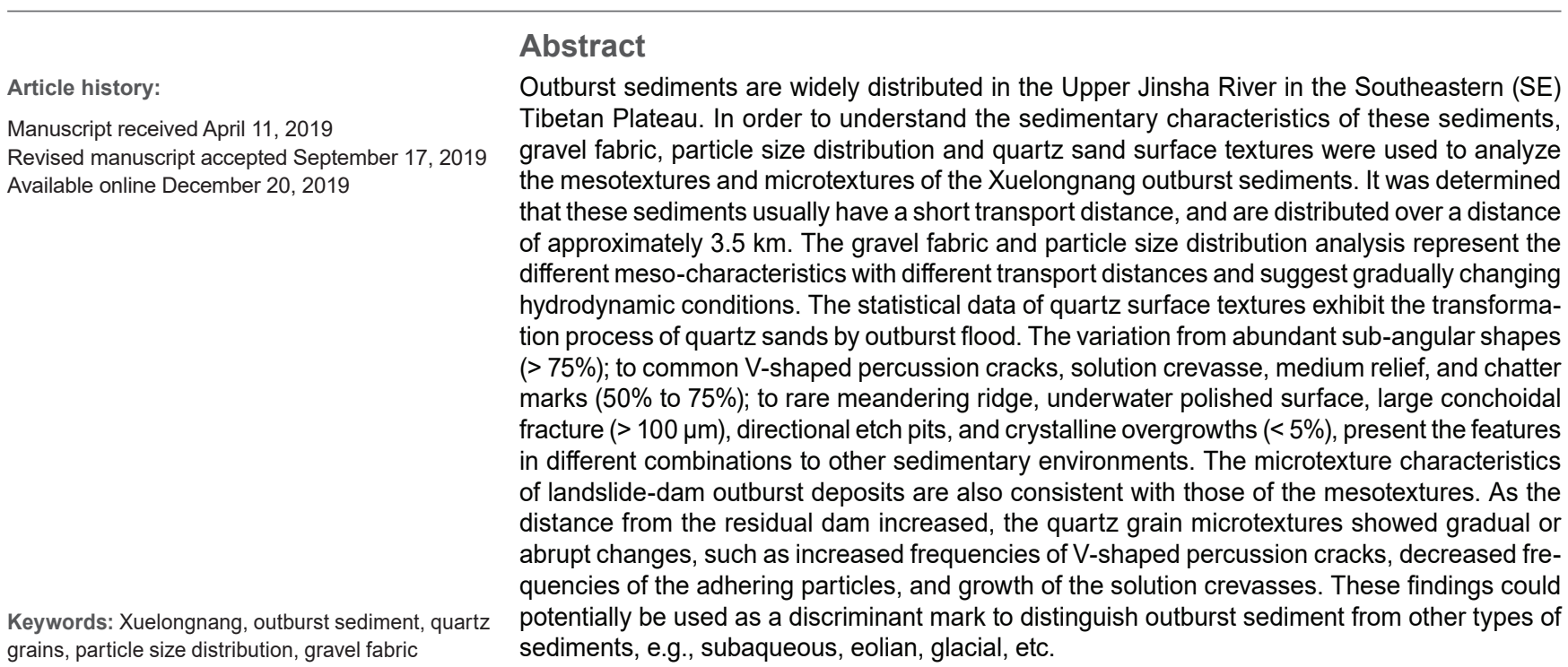

\section{INTRODUCTION}

Scanning electron microscopy (SEM) has been widely utilized to collate the observed surface microtextures of quartz grains characterized by grain migration and sedimentary environments. (KRINSLEY \& TAKAHASHI, 1962; HAMILTON \& KRINSLEY, 1967; WHALLEY \& KRINSLEY, 1974; HELLAND \& DIFFENDAL, 1993; MAHANEY et al., 2001; KRINSLEY, 2011, IMMONEN, 2013; VOS et al., 2014; CHEN et al., 2019). This method is able to amplify the nanoscale microtexture enough times for examinations to be completed and has been applied in the study of sediment from other sources, such as grains from glacial sediment (MAHANEY \& KALM, 1995); glacial tills (MAHANEY et al., 1988; MAHANEY et al., 1996); ice-drift sediment (MAHANEY \& ANDRES, 1991; SMALLEY \& GLENDINNING, 1991; MAHANEY, 1992); loess glaciers (PYE, 1983; KENIG, 2006); eolian sediment (MAHANEY \& ANDRES, 1996; CHAKROUN et al., 2009); parent rock (MOLEN, 2014) and tsunami deposits (COSTA et al., 2012). However, it is less common to use SEM techniques to study the microtexture of quartz grains in palaeo-landslide outburst sediment. Therefore, based on the measurements of the gravel fabric and analysis of the particle size distribution of the sand grains (MAHANEY \& KALM, 1995), and the surface textures of quartz grains, the sedimentary process of the outburst sediment can be better understood.
Although it can be difficult to determine the exact shape of parent-rock quartz grains and their microtexture characteristics, it can be deduced from previous research on mechanically-released quartz in cave walls (MAHANEY \& KALM, 1995), and weathering release processes (MOLEN, 2014). Clearly, the transported grains in the outburst deposits were affected by the non-uniform stresses within different parts of a large water mass. It included many variable factors, such as transport distances, velocity and sediment concentration, which resulted in the formation of a variety of different sedimentary characteristics (e.g., gravel fabric; quartz surface textures, and particle size distribution).

This study analyzes the sedimentary characteristics of the Xuelongnang outburst deposits from multiple aspects. The samples collected were analyzed to become the discriminant criterion of the outburst deposits. It was thought that the sediment was deposited relatively rapidly along the direct contact between the landslide-dam outburst flooding and the underlying river bed, flood plain, and river terraces. The maximum thickness of the sediment was approximately $15 \mathrm{~m}$, and the length was approximately $3.5 \mathrm{~km}$ (CHEN et al., 2013; CHEN \& CUI, 2015). During the sedimentary process, the sediments were further transformed by floodwaters and formed specific microtextures. Here, the results of the field investigations and sediment sampling were used for laboratory experiments in order to obtain the sedimentary parameters, which included the gravel fabric (ori- 

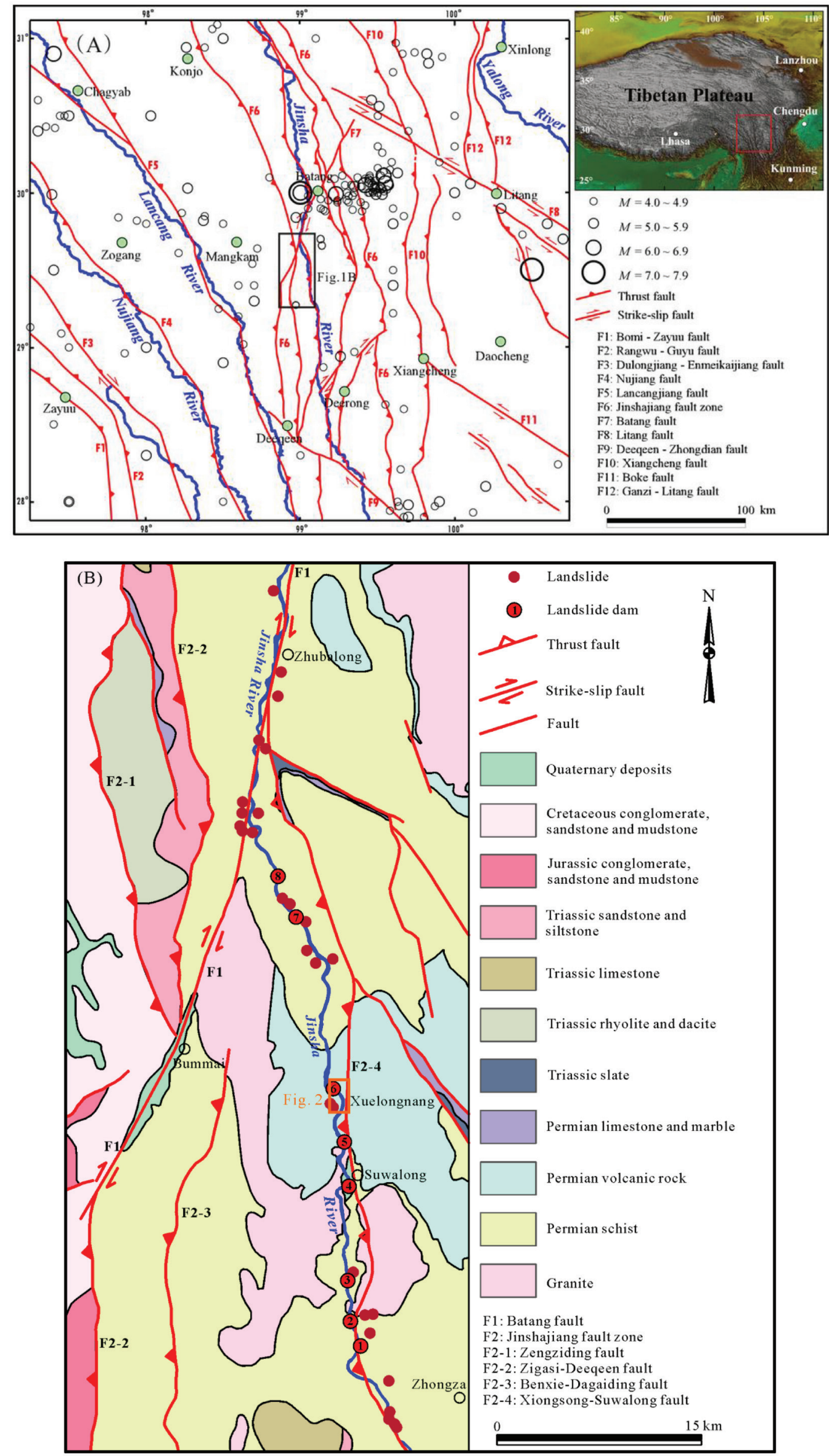

Figure 1. Location of the study area in the southeastern margin of the Tibetan Plateau. (A) Location map of the study area. (B) Geological map of the Xuelongnang Reach of the upper Jinsha River. 
entation of the Axis a and Plane ab in gravels and pebbles), and particle size distribution of the sand grains, as well as the surface microtextures of the quartz grains.

\section{STUDY AREA}

The Xuelongnang outburst sediments are located in the upper reaches of the Jinsha River, on the southeast margin of the Qinghai-Tibet Plateau, in southwest China, approximately $50 \mathrm{~km}$ to

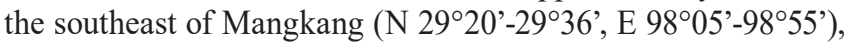
as detailed in Figure 1. (CHEN et al., 2018). The study area has a maximum altitude of $6,000 \mathrm{~m}$, and a minimum altitude of 2,200 $\mathrm{m}$. Also, the largest relative relief is $3,800 \mathrm{~m}$, where the river level is approximately $2,300 \mathrm{~m}$. Since the Late Cenozoic, due to uplift of the southeast margin of the Qinghai-Tibet Plateau and strong river cutting action (MA et al., 2018), morphogenesis has produced a gorge in the upstream section of the Jinsha River. Where the river runs between Xuelongnang and Wangdalong, its elevation drops to about $2,300 \mathrm{~m}$, with a valley width in Xuelongnang of between 100 and $200 \mathrm{~m}$. The slopes of the rock walls on both sides of the gorge are approximately 40 degrees. The valley between Xuelongnang and Wangdalong has a subtropical arid climate, with an annual precipitation of only $400 \mathrm{~mm}$, with the rainfall concentrated mainly between June and October. In Xuelongnang, Neotectonic movement is considered to be active. Also, the Xiongsong-Suwalong Active Fault, which is the major fault of the Jinsha River Fault Zone, crosses eastern Xuelongnang (Figure 1). In the valley, lithologically the rock outcrops consist mainly of Permian schist, igneous rock, and marble. In this region, landslides are fairly common due to the intense development of joints with significant physical weathering and the influence of the active faults in the Jinsha River valley. In this study, based on geological and topographic maps and the distance of the sediment from the residual dam, the sediments were divided into three sections: upstream sediment, midstream sediment, and downstream sediment, as shown in Figure 2.

\section{METHODOLOGY}

Both field investigation and laboratory examination were undertaken. In order to describe the gravel fabric, gravel samples $(>2 \mathrm{~cm})$ were randomly selected to measure the length and trend of axis a, as well as the orientation of the plane ab.

For the purpose of collecting samples for analysis of particle size distribution and quartz grain microtextures, two typical outcrops were selected in each of the three sediment sections (Figure 2) for a total of eight sampling areas. In each sampling area, $50 \mathrm{~cm} \times 50 \mathrm{~cm}$ squares were drawn on the surface. Sediments from the surface to a depth of $30 \mathrm{~cm}$ were removed for sampling. We used a chisel and shovel to collect a mixture of coarse gravel and fine sand, and then fine sand was picked from the middle part of the mixture (two samples for each square, and each sample weighed more than $200 \mathrm{~g}$ ). The particle size distributions of the samples were obtained by following the process described by MAHANEY (1995), then the sand size particles $(0.063-2 \mathrm{~mm})$ were screened out. The fines $(<0.063 \mathrm{~mm})$ were also separated, and a laser diffraction particle size analyzer (Mastersizer 3000) was used in order to determine the percentages of silt and clay. The method proposed by VOS et al. (2014) was then used to pretreat the sand samples as follows:

(1) The sands were dried, and then typically separated (quartered), until about $10 \mathrm{~g}$ of sandy grains remained;

(2) The sand was placed in a $1 \mathrm{~mol} / \mathrm{L}$ HCL solution and boiled for 10 minutes to remove carbonates and iron oxide;

(3) The sand was washed at least three times using deionized water, until only clean water could be poured out;

(4) The sand was placed in a $1 \mathrm{~mol} / \mathrm{L}$ hydrogen peroxide solution and boiled for 10 minutes to remove the clay and organic matter;

(5) The sand was washed at least three times with deionized water until only clean water could be poured out;

(6) Finally, the sand samples were dried at $60{ }^{\circ} \mathrm{C}$ for 12 hours.

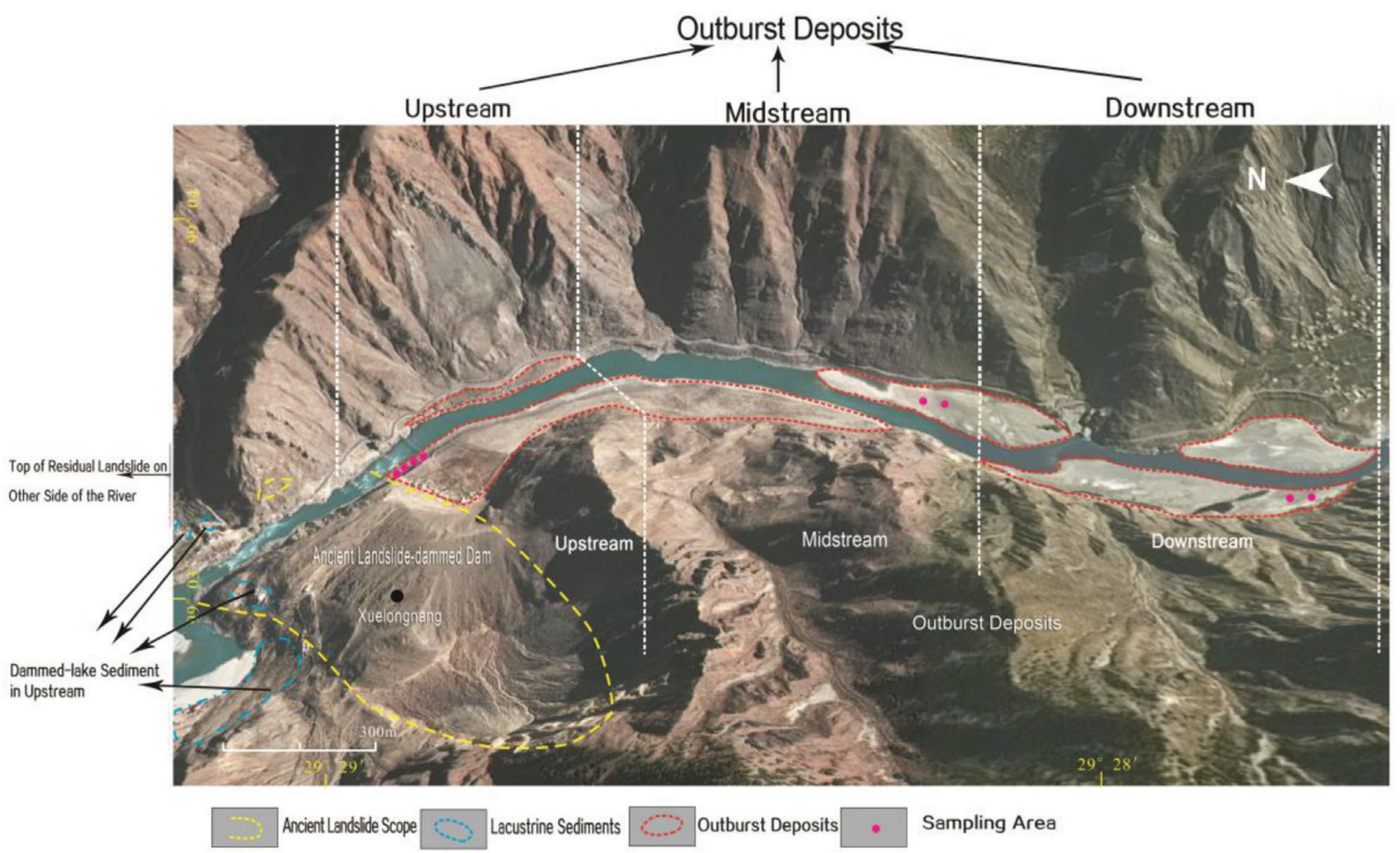

Figure 2. Distribution of the outburst sediment from the Xuelongnang landslide-dammed lake. 
Since it was believed that the formation of microtextures may be associated with grain size (MAHANEY, 2002), grains of similar size were selected. In this study, quartz grains with sizes ranging between 0.2 and $0.5 \mathrm{~mm}$ were selected for microstructural analysis. A ZEISS SUPRA TM, from the Science Institute of the China University of Geosciences (Beijing), was used for the observations. For each sample, 10 to 20 grains were selected to fix on the double-sided adhesive of the SEM samples in particular orientations. The sample was then subject to gold sputtering, as it had been previously determined that gold provides better resolution than other heavy metals or carbon (VOS et al., 2014). Also, gold coating can reduce beam penetration, which in turn leads to clearer images. However, the most important objective was to minimize the surface charge. In this study, the samples were sputtered and coated, and a $40 \mathrm{~mA}$ current was applied for 300 seconds, in order to obtain a gold coating of approximately $250 \mathrm{~nm}$.

\section{RESULTS AND DISCUSSIONS}

\subsection{Sedimentary structure}

Examination of the landslide-dam outburst sediment revealed a fining-downstream pattern within the deposit. The upstream sediment contained many rock blocks, boulders, and erratic blocks, which were either clast-supported or matrix-supported. Silty and fine sand formed the matrix, which filled in the inter-grain gaps and pores. In the midstream sediment, large amounts of gravel and pebbles were observed, while boulders or erratic blocks were rarely observed. The downstream sediments were observed to have large amounts of smaller gravel, pebbles, and sand with a crude stratification. Also, gravel imbricated structures appeared in some of the coarse layers, which contained significantly more silty and fine sand than the coarse layers observed in the sediments of the other two sections.

\subsection{Gravel fabric}

It is known that large sized gravel usually indicates greater hydrodynamic activity. However, when analyzing the hydrodynamic effects of sedimentary processes, the morphology of the gravel is also definitely very important. To a large extent, the gravel fabric of outburst sediment can maintain and reflect both kinematic and dynamic information. Therefore, in order to achieve a dynamic equilibrium state, the morphology of highspeed mobile grains must be consistent with the direction and magnitude of the force, so that the dynamic energy of the grains can reach the minimum level (for example, a steady state). In addition, the grains' position adjustments are also associated with the development of the gravel fabric. Under general conditions, the direction of the long axis (Axis a) of fluvial sedimentary gravel generally indicates the movement direction of the grain and also shows a large number of the changes related to differential resistance. In an outburst mass with high-speed movement, the tendency of the gravels' maximum plane (Plane ab) usually indicates the maximum stress direction of the grains with a forced movement (pushing movement), and the value of the dip angle could potentially reflect the ratio between the horizontal and vertical stresses. In other words, a larger angle indicates greater horizontal stress, and vice versa.

The field investigations revealed the closer the sediment was to the residual dam, the greater the size of the gravel (Table 1: $6.3 \mathrm{~m}$, $2.3 \mathrm{~m}$, and $1.7 \mathrm{~m}$ ). These results were in line with the expectations, since increasing distance from the residual dam leads to decreases in the hydrodynamics, and thereby promotes decreases
Table 1. Axis a data from the Xuelongnang outburst sediment.

\begin{tabular}{ccc}
\hline Location & maximum particle a-axis (average) $/ \mathrm{m}$ & a-orientation (average) $/{ }^{\circ}$ \\
\hline Upstream & 6.3 & 287.5 \\
\hline Midstream & 2.3 & 265.4 \\
\hline Downstream & 1.7 & 152.8 \\
\hline
\end{tabular}
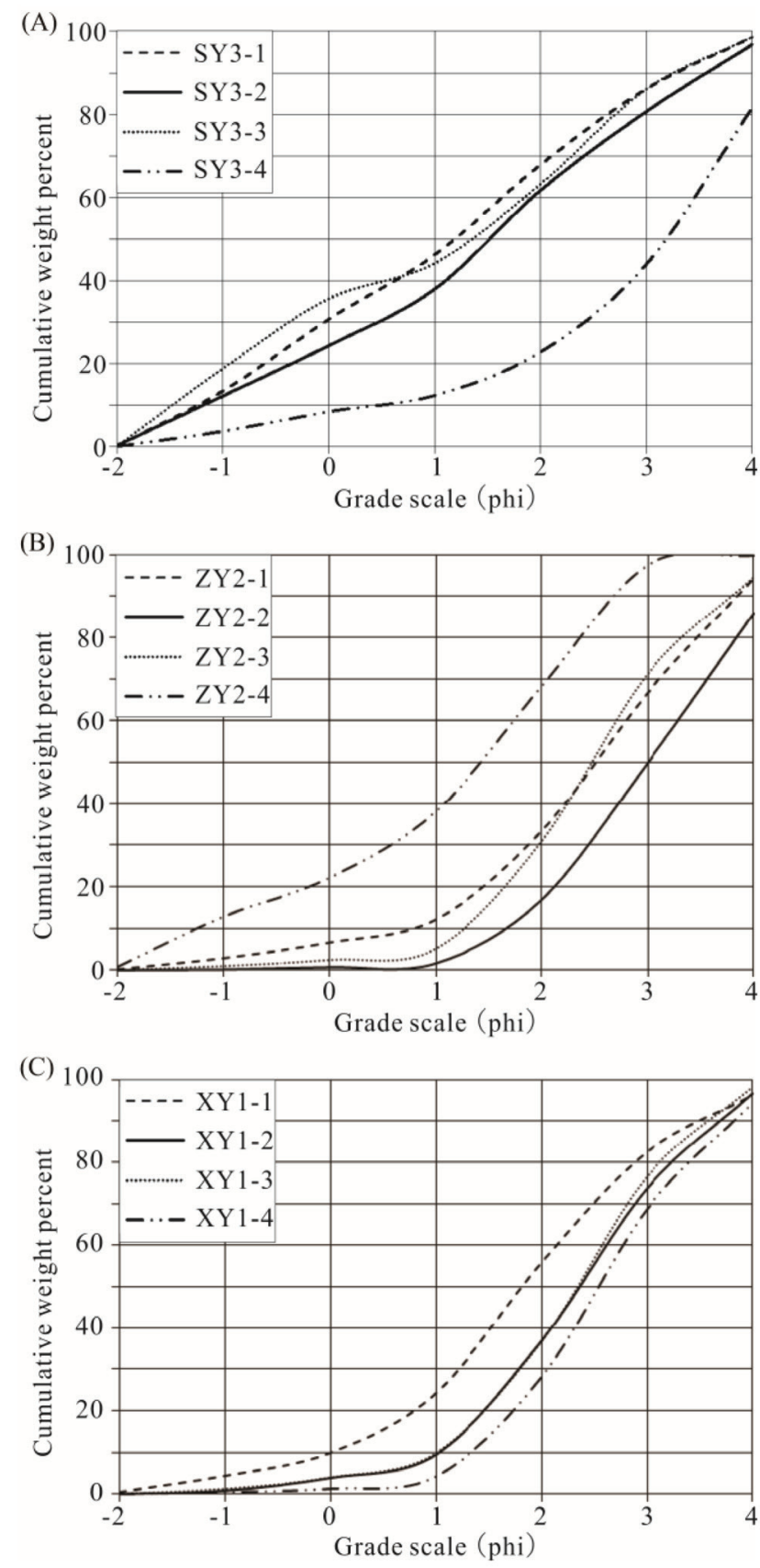

Figure 3. article size distribution curves for: $(A)$ the upstream sediment, $(B)$ the midstream sediment $(C)$ the downstream sediment.

in the size of the transported particles. Similarly, the orientation of Plane ab was determined to be strongly influenced by the hydrodynamics (principal horizontal stress), as the orientation of the Plane $a b$ for the grains in the study area was found to be close to that of the river's trend. These findings suggest that the hydrodynamic direction of water flow was the main factor influencing of the grains' orientation during transportation and deposition. In addition, outburst flooding was characterized by strong explo- 
Table 2. Grain size component and mean grain size of the Xuelongnang outburst sediment.

\begin{tabular}{|c|c|c|c|c|c|c|c|c|}
\hline \multirow{2}{*}{ Location } & \multirow{2}{*}{ Sample } & \multirow{2}{*}{$\begin{array}{l}\% \text { Gravel } \\
(2 \sim 4 \mathrm{~mm})\end{array}$} & \multirow{2}{*}{$\begin{array}{c}\text { \% Sand } \\
(0.063 \sim 2 \mathrm{~mm})\end{array}$} & \multirow{2}{*}{$\begin{array}{c}\% \text { Silt } \\
(0.002 \sim 0.063 \mathrm{~mm})\end{array}$} & \multicolumn{4}{|c|}{ Percentile } \\
\hline & & & & & 25th & 50th & 75th & mean phi \\
\hline \multirow{4}{*}{ Upstream } & SY3-1 & 0.13 & 85.05 & 14.82 & 0.4 & 1.2 & 2.4 & 1.1 \\
\hline & SY3-2 & 0.23 & 84.40 & 15.38 & 0.0 & 1.5 & 2.7 & 1.4 \\
\hline & SY3-3 & 0.05 & 79.81 & 20.13 & 0.7 & 1.4 & 2.5 & 1.1 \\
\hline & SY3-4 & 0.00 & 77.77 & 22.23 & 2.1 & 3.2 & 3.8 & 2.9 \\
\hline \multirow{4}{*}{ Midstream } & ZY2-1 & 0.17 & 91.20 & 8.63 & 1.7 & 2.5 & 3.3 & 2.5 \\
\hline & $Z Y 2-2$ & 0.01 & 85.72 & 14.27 & 2.3 & 3.0 & 3.7 & 3.0 \\
\hline & ZY2-3 & 0.00 & 93.61 & 6.39 & 1.8 & 2.4 & 3.1 & 2.5 \\
\hline & $Z Y 2-4$ & 0.74 & 86.18 & 13.08 & 0.2 & 1.4 & 2.2 & 1.1 \\
\hline \multirow{4}{*}{ Downstream } & XY1-1 & 0.46 & 91.37 & 8.17 & 1.0 & 1.8 & 2.7 & 1.9 \\
\hline & $X Y 1-2$ & 0.03 & 95.86 & 4.11 & 1.6 & 2.3 & 3.1 & 2.4 \\
\hline & $X Y 1-3$ & 0.05 & 96.98 & 2.97 & 1.6 & 2.3 & 2.9 & 2.4 \\
\hline & $X Y 1-4$ & 0.04 & 93.88 & 6.08 & 1.9 & 2.5 & 3.2 & 2.6 \\
\hline
\end{tabular}

sive mass flow during a short period of time. The dip angle of the outburst sediment was measured to be generally greater than $35^{\circ}$. Also, due to the flooding and narrow valleys, the trend of Axis a (Table 1) displayed no obvious differences, which suggested that the tendency of flooding was inconsistent over a smaller range, and likely affected by the narrow and tortuous channel.

\subsection{Particle size distribution}

The particle size distribution of the outburst sediment was analyzed in this study (Fig. 3), in an attempt to identify whether the changes in the sand content (especially the medium sand) were related to the differences in the microtexture type and assemblage on the surface of the quartz grains. Overall, the sand content of the downstream sediment was found to be the highest (Table 2), the sources of which may have been the landslide lake, as well as the residual dam mass. Table 2 . shows the midstream sediment also contained large amounts of coarse sand (1 to $2 \mathrm{~mm}$ grainsize). The upstream sediment curve (Figure 3a) was almost a straight-line segment, with the exception of samples SY3-4 and ZY2-4. Since these samples were collected near the residual dam mass, it may have included finer-grained material from the residual dam or lake sediments upstream. The midstream sediment curve (Figure $3 \mathrm{~b}$ ) showed higher contents of fine and silty sand, with poor sorting characteristics. It was determined that as the distance between the sediment and the residual dam increased, the sand content increased, while the silt content decreased. The downstream sediment curves (Figure 3c) feature three almost straight-line segments, which indicates that this section of sediment had the poorest sorting. The downstream sediment was determined to have the highest content of fine sand and the lowest content of silty sand. The analyses indicate that among all the samples, the clay content $(<0.002 \mathrm{~mm}$ ) was minimal (mainly zero, or almost negligible). The minimal clay content may be due to a lack of lacustrine sediment in the provenance area, short sedimentary time, and continuous fluctuations in the water energy, which inhibit development of the required hydrostatic environment for clay sedimentation to occur. These conditions are known to be characteristic of outburst sediments and distinguish them from other sources of sediment (MAHANEY \& KALM, 2000; STUUT et al., 2014; LUO et al., 2015).

It can be seen in Table 2. and in Fig. 3a, b that the upstream sample SY3-4 and midstream sample ZY2-4 show differently shaped grain size distribution curves and average particle size than the other samples within the same group. These anomalies may be due to mixing with material from the residual dam mass and material from the adjacent section of sediment. The features of quartz grain surface textures at different segments were analyzed using a scanning electron microscope (SEM).

\subsection{Surface microtextures of quartz grains}

In this study, SEM was used to observe 172 quartz grains using nearly 1,000 photo images. The quartz surface texture classification proposed by VOS et al. (2014) was used in combination with the actual observations. A total of 36 types of possible surface microtextures were divided into three types: mechanical characteristics, chemical characteristics, and mechanical/chemical characteristics. The frequency of occurrence of each microtexture was calculated as a percentage of the samples exhibiting the microtexture. Based on the frequency of occurrence, microtextures were classified as abundant (>75\%); common (50\% to $75 \%$ ); sparse $(5 \%$ to $50 \%)$; and rare $(<5 \%)$.

For the quartz grains among the outburst samples at different locations from the upstream to downstream, it was determined that the most abundant microtexture was a sub-angular shape (Plate 1. a, b). Common microtextures included V-shaped percussion cracks (Plate 1. c, d), medium relief (Plate 2. c), solution crevasses (Plate 2. a), and chatter marks (Plate 2. d). Sparse microtextures include low relief, adhering particles (Plate 2. e, f), and disc concave pits (Plate 1. e, f). Rare microtextures included underwater polished surfaces (Plate 2. b), large conchoidal fractures $(>100 \mu \mathrm{m})$, directional etch pits, crystalline overgrowths, and meandering ridges. Imbricate grinding features and scaling were not observed in any of the samples (Table 3). In addition, the frequency of occurrence of the microtextures in each sediment section revealed gradual changes within the outburst deposit. The frequency of several microtextures increased with increasing distance from the residual dam. Examples include V-shaped percussion cracks, small conchoidal fractures $(<10 \mu \mathrm{m})$, graded arcs, parallel striations, and siliceous globules (mainly as mechanical characteristics). It was most interesting to observe that the frequency of adhering particles was gradually reduced, which indicated that the water chemistry was able to remove the particles attached to the grain surfaces. It is also possible that particles close to the residual dam mass collided more frequently and generated more impact debris available for adhering to the grains than particles farther downstream. The collision between the grains of the samples which were closer to the residual dam mass was more frequent, which led to more impact debris adhering to the grains. 


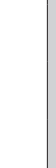

ฮु

36.Arcuate/circular/polygonal cracks

35.Adhering particles

34.Chatte rmarks

33.Elongated depressions

32.High relief

过 31.Medium relief

30.Low relief

29.Underwater polished surface

28.Crystalline overgrowths

27.Silica pellicle

즌 26.Silica flowers

25.Silica globules

24.Scaling

23.Solution crevasses

22.Solution pits

21.Directional etch pits
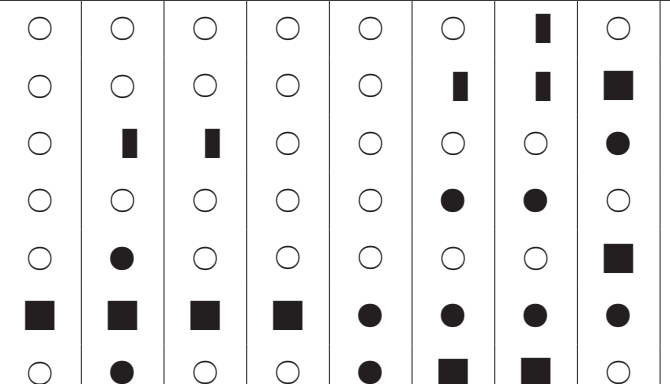

-

\begin{tabular}{|l|l|l|l|}
\hline & $\bigcirc$ & $\mathbf{I}$ & $\mathbf{\square}$
\end{tabular}

20.Disc-shaped concave pits

19.Imbricate grinding features

18.Parallel striations

17.Abrasion fatigue

16.Bulbous edges

15.Crescentic percussion marks

14.Upturned plates

13.Straight/curved grooves and scratches

12.V-shaped percussion cracks

11.Graded arcs

Uू 10. Flat cleavage surfaces

9.Meandering ridges

8.Straight steps

7.Arcuate steps

6.Large conchoidal fracture $(>100 \mu \mathrm{m})$

5.Medium conchoidal fracture $(<100 \mu \mathrm{m})$

4.Small conchoidal fracture $(<10 \mu \mathrm{m})$

3.Circular contour

2.Subangular contour

1.Angualr contour

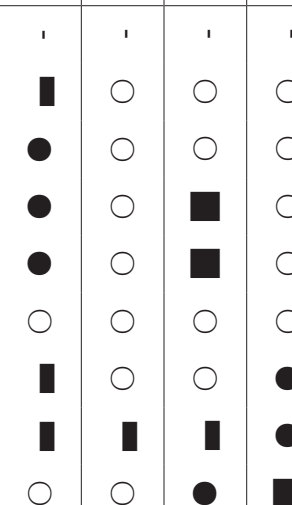

1

'

\begin{tabular}{ll|l}
1 & 1 \\
\hline & 0
\end{tabular}

o

- 0 【

- 0

- 0 ! 


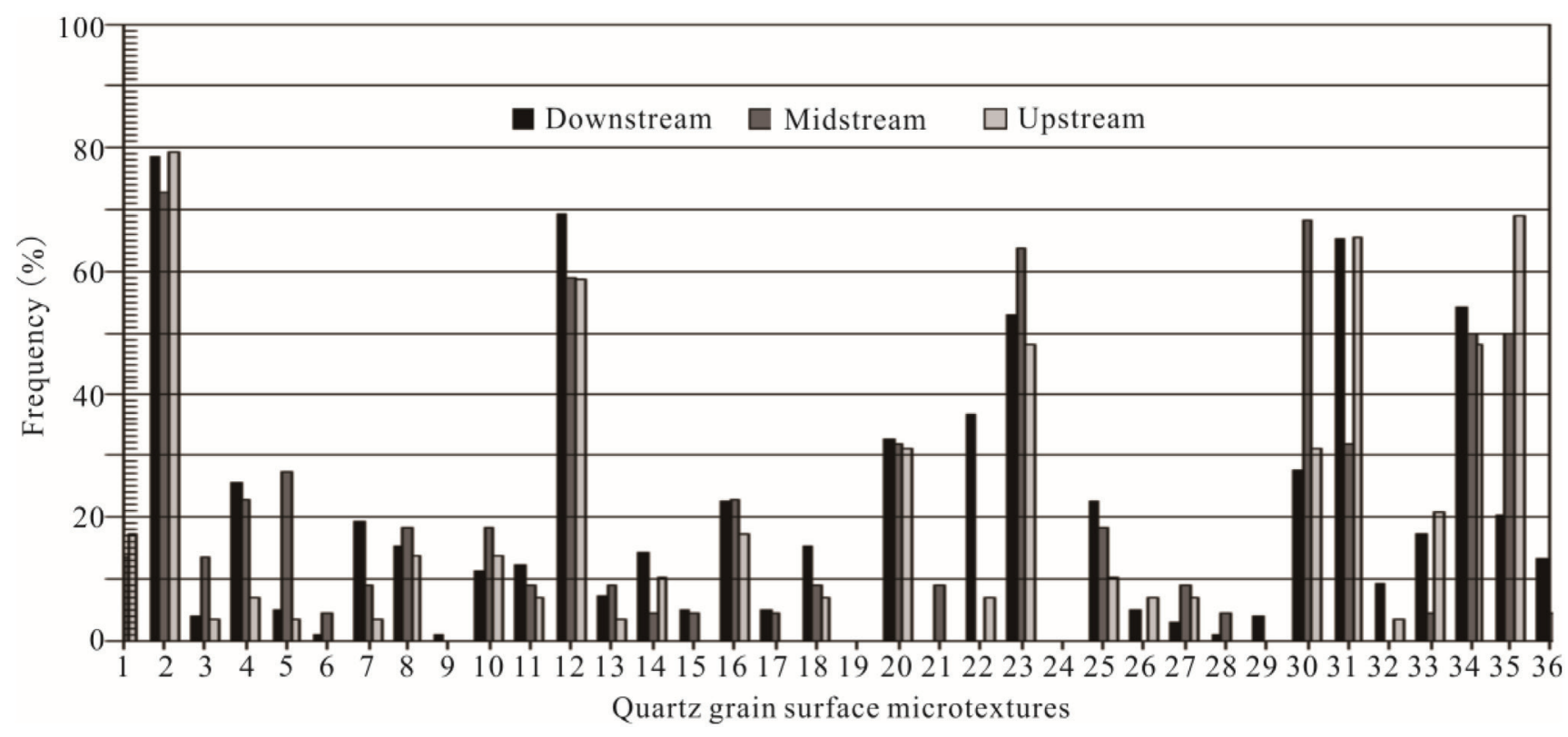

Figure 4. Histogram of quartz surface microtextures in the Xuelongnang outburst sediments. At least 10 grains per sample were analyzed. The numbers in the vertical axis of the curve correspond to the structure numbers listed in Table 3.

\subsubsection{Mechanical Characteristics}

The roundness parameter describes the degree of roundness or angularity of grains on the mesoscopic scale. Grains are described as angular, sub-angular, or rounded. The grain angularity is not only mainly related to the migration method, migration distance, granularity, and time, but also is correlated to the main shape of the grains in the parent rock (KLEESMENT, 2009; COSTA et al., 2013). The sub-angular contoured grains are usually associated with an upper flow or intertidal zone, of which the formation requires violent abrasion to make grain edges round (MAHANNEY, 2002; Table 3). In addition, chemical effects can also change the grain contour, such as dissolution and precipitation. However, these effects are different from the characteristics of mechanical abrasion. In outburst sediment, abundant sub-angular contours indicate that the sediments are not experiencing long-term water abrasion. However, rapid deposition is known to be consistent with the characteristics of the gravel fabric and granularity distribution.

A meandering ridge is a slightly curved intersection line between conchoidal fractures, which can cross the grain's surface. It features the typical characteristics of grains located in such environments as desert sand transport, coastal dunes, and glaciers (Table 3). Therefore, it is known to be rare in outburst sediment.

Similarly, imbricate grinding features exist only in glacial grinding conditions (Table 3). Therefore, findings of zero percentages of these in outburst sediment are understandable.

$\mathrm{V}$-shaped percussion cracks are approximately triangular concave pits with maximum diameters of $5 \mu \mathrm{m}$, and average depths of $0.1 \mu \mathrm{m}$. Usually, V-shaped percussion cracks have random orientations. This is mainly due to the fact that the grains are in high-energy underwater environments (such as coastal areas, braided rivers, and glacial rivers), and the collision between grains is random. In some special conditions, such as a tsunami, the grains will show rapid abrasion in a short period (VOS et al., 2014; Table 3). It is common that, during the process of a dam burst, the dam-burst flooding is characterized by a very large amount of energy as it flows in narrow valleys, which leads to frequent violent collisions between the suspended grains. However, with increased distances from the residual dams, the larger grains tend to settle, while the collision change between the smaller grains in the water becomes obvious. Therefore, their frequency of occurrence downstream will be larger than in the upstream areas.

A disc concave pit is similar to a V-shaped percussion crack and is caused by the collision between grains. The formation of these pits requires more energy, as well as more rounded grains. The frequency of occurrence of concave disc pits has increased (Figure 4), though they are not always obvious, mainly due to the collision energy not being increased (energy may also have been reduced). The quantity of the rounded grains in the downstream sediment will be greater than the upstream and midstream areas. Also, the flow migration and transformation play vital roles on the particle distribution.

\subsubsection{Chemical Characteristics}

Directional etch pits are usually formed in crystal planes with widths of between 1 and $30 \mu \mathrm{m}$. They can be distinguished from the $\mathrm{V}$-shaped percussion cracks by their regular and directional appearance. The occurrence of directional etch pits can be attributed to dislocations and defects within the crystal lattice, where the quartz is more likely to dissolve. Since dissolution takes a long time, it would be difficult for rapid dam-burst flooding to produce directional etch pits.

Solution crevasses are dissolved cracks on grain surfaces, which are usually related to dissolved pits with successive formation times. For example, a dissolved pit forms first, and then a solution crevasse is formed on this basis (KRINSLEY \& DOORNKAMP, 1973). In this study, it was found that, with the increased distances from the residual dam, the dissolved pits were gradually reduced, while the solution crevasses increased. These findings illustrate the genetic relationship between these features. In flooded environments, the dissolution and diagenesis processes can generate solution crevasses. The gradual downstream increase in the frequency of occurrence of solution crevasses is thought to result from the transport of the downstream sediment 
in deeper underwater conditions for longer times, which leads to dissolved pits continuing to form solution crevasses.

Scaling describes a wide range of surface splitting, which has resulted in the fragmented spalling of grains (KRINSLEY \& DOORNKAMP, 1973). It is a final product of chemical modification, or the last stage of a chemical effect. It is known to be very rare within the outburst sediment, which may be due to the excessively short effect time, along with falling water levels. Dam-burst floods move so fast that there is not enough time to further erode the grains. Silica pellicle is deposited as a thin layer of silica on the quartz surfaces. It usually occurs after the formation of silica globules, and silica flowers are the third phase of silica precipitation. Also, it usually covers other shallow mechanical microtextures, which leads to greater difficulties in the recognition of some of the characteristics. When silica has enough time to precipitate under water, silica pellicles can be formed. However, dam burst processes are very rapid, which makes them unable to meet this requirement. Therefore, silica pellicles are very rare within outburst sediment.

\subsubsection{Mechanical and Chemical Characteristics}

The relief indicates the smoothness of the grain's surface and can be subdivided into three categories: low, medium, and high relief. The collision between grains and/or reformation will lead to relief irregularity. Generally, low and medium relief are formed in diagenetic environments. However, in some special cases, such as in dam burst environments, they can be generated by dissolution processes and precipitation. For example, dissolution and precipitation can erase or fill relief. Therefore, low and medium relief tend to range from sparse to common among outburst sediments, while little high relief has been observed.

Chatter marks are large curved grooves on grain surfaces, which lack clear splitting phenomena (PETERKNECHT \& TIETZ, 2011). Usually, they are the product of mixing actions, including mechanical actions, passive collisions, and chemical reactions during the processes of sediment transport. Therefore, a particular sedimentary environment cannot be identified by their appearance (BULL, 1981; PETERKNECHT \& TIETZ, 2011; Table 3). The only possible conclusion is that they are associated with underwater effects.

Adhering particles are all the fragments or grains attached to the surface of the quartz grains, of which the compositions and sizes are variable (HIGGS, 1979). They have extensive sources, including parent rock, other mineral grains, or diagenetic products. However, the adhering particles are easily destroyed and could not provide enough accurate information. As a result, this percentage change played a limited role in this study and can only provide a supplementary method on the diamicton discrimination.

\section{CONCLUSIONS}

It has been found that dam-burst flooding induces special gravel fabric characteristics, variable particle size distributions, and significant damage to the quartz grains. In this study, in accordance with the distance from the residual dam, the sediments were divided into three sections: upstream, midstream, and downstream. The gravel fabric characteristics were found to be consistent with the short-term strong explosive high-flow hydrodynamic conditions of dam-burst flooding, of which the tendency of Plane ab was close to the river's trend, with a dip angle generally greater than $35^{\circ}$. The laser granularity test showed that almost no clay minerals could be detected in the samples of outburst sediment.
These findings confirmed that the sediments were not mixed with the landslide-lake sediment and had not undergone a long static ambient environment. The present results indicate that each section of sediment had a distinct gravel fabric and particle size distribution. Due to the gradual reduction in stream capacity from the dam-burst mouth to the downstream areas, it was concluded that gravel size increased with proximity to the residual dam. The particle size distribution showed a similar decrease in grain size with distance from the residual dam. Therefore, the average particle size value assisted in distinguishing the different environments for each section of sediment, with the larger average particle size showing greater stream capacity, and vice versa.

The scanning electron microscopy results showed that the frequency distributions of the surface microtextures for the quartz grains in the outburst sediment were abundant in the case of sub-angular shape category $(>75 \%)$; common in the V-shaped percussion cracks, solution crevasses, medium relief, and chatter mark categories (50\% to $75 \%$ ); and rare in the meandering ridge, underwater polished surface, large conchoidal fracture $(>100$ $\mu \mathrm{m})$, directional etch pit, and crystalline overgrowth categories. Also, no imbricate grinding features or scaling were apparent in any of the samples. Especially, the frequency percentages of the various microtextures in each section of the sediment showed a gradual change rule. In some cases, they were found to increase with distance from the residual dam, as in the case of V-shaped percussion cracks, which indicated that the hydrodynamics had gradually reduced. Such characteristics can potentially be used to identify outburst sedimentary environments. However, fluctuations were determined to exist in the other characteristics, such as the solution crevasses. This may have been due to the participation of a late fluvial effect which induced complex conditions. It was interesting to note that some of the characteristics were reduced, such as adhering particles. Alternatively, the collisions between the grains of the samples closer to the residual dam were more frequent, which led to more impact debris becoming attached to the grains' surfaces. The quartz grains from the outburst sediment are compared with the grains from underwater, aeolian, and glacial sediments etc (Table 3), which provide an identification basis for outburst sedimentary deposits. These mesoscopic and microscopic works reveals sedimentary characteristics of the landslide-dam outburst deposits, indicating an obvious change of transport processes.

\section{ACKNOWLEDGEMENT}

This study was supported by the National Natural Science Foundation of China (grants no. 41571012 and no. 41230743) and the National Key R\&D Program of China (grant no. 2018YFC1505003). We sincerely thank the editor and the anonymous reviewers for their comments which substantially improved the manuscript.

\section{REFERENCES}

BULL, P.A. (1981): Environmental reconstruction by electron microscopy.- Progress Physical Geography, 5/3, 368-397. doi: 10.1177/030913338100500302

CHAKROUN, A., MISKOVSKY, J.C. \& ZAGHBIB-TURKI, D. (2009): Quartz grain surface features in environmental determination of aeolian Quaternary deposits in northeastern Tunisia.- Mineralogical Magazine, 73/4, 607-614. doi: 10.1180/minmag.2009.073.4.607

CHEN, R.C., CHEN, J., MA, J.X. \& CUI, Z.J. (2019): Quartz grain surface microtextures of dam-break flood deposits from a landslide-dammed lake: A case study.Sedimentary Geology, 383, 238-247. doi: /10.1016/j.sedgeo.2019.02.010

CHEN, J. \& CUI, Z. (2015): Discovery of outburst deposits induced by the Xuelongnang Paleolandslide-dammed lake in the upper Jinsha River, China and its environmental and hazard significance.-Acta Sedimentologica Sinica, 33/2, 275-284 (in Chinese,with English Abstr.). 
CHEN, J., DAI, F., LV, T. \& CUI, Z. (2013): Holocene landslide-dammed lake deposits in the Upper Jinsha River, SE Tibetan Plateau and their ages.- Quaternary International, 298, 107-113. doi: 10.1016/j.quaint.2012.09.018

CHEN, J., ZHOU, W., CUI, Z.J., LI, W.C., WU, S. \& MA, J.X. (2018): Formation process of a large paleolandslide-dammed lake at Xuelongnang in the upper Jinsha River, SE Tibetan Plateau: constraints from OSL and $14 \mathrm{C}$ dating.- Landslides, 15, 2399-2412. doi: 10.1007/s10346-018-1056-3

COSTA, P.J.M., ANDRADE, C., DAWSN, A.G., MAHANEY, W.C., FREITAS, M.C., PARIS, R. \& TABORDA, R. (2012): Microtextural characteristics of quartz grains transported and deposited by tsunamis and storms.- Sedimentary Geology, 275, 55-69. doi: 10.1016/j.sedgeo.2012.07.013

COSTA, P.J.M., ANDRADE, C., MAHANEY, W.C., MARQUES DA SILVA, F., FREIRE, P., FREITAS, M. C., JANARDO, C., OLIVEIRA, M.A., SILVA, T., LOPES, V. (2013): Aeolian microtextures in silica spheres induced in a wind tunnel experiment: Comparison with aeolian quartz.- Geomorphology, 180-181, 120-129. doi: 10.1016/j.geomorph.2012.09.011

FOLK, R.L. (1980): Petrology of Sedimentary Rocks.- Hemphill Press, Austin, Texas, $170 \mathrm{p}$.

HAMILTON, W. \& KRINSLEY, D.H. (1967): Upper Palaeozoic glacial deposits of South America and Southern Australia.- Geological Society America Bulletin, 78/6, 783-799

HELLAND, P.E., DIFFENDAL, R.F., HELLAND, P.E. \& DIFFENDAL, R.F. (1993): Probable glacial climatic conditions in source areas during deposition of parts of the Ash Hollow Formation, Ogallala Group (late Tertiary), of western Nebraska.- American Journal Science, 293/8, 744-757. doi: 10.2475/ajs.293.8.744

HIGGS, R. (1979): Quartz-grain surface features (texture) of Mesozoic-Cenozoic sands from the Labrador and Western Greenland continental margins.- Journal Sedimentary Petrology, 49/ 2, 599-610.

IMMONEN, N. (2013): Surface microtextures of ice-rafted quartz grains revealing glacial ice in the Cenozoic Arctic.- Palaeogeography, Palaeoclimatology, Palaeoecology, 374, 293-302. doi: 10.1016/j.palaeo.2013.02.003

KENIG, K. (2006): Surface microtextures of quartz grains from Vistulian loesses from selected profiles of Poland and some other countries.- Quaternary International, 152-153/15, 118-135. doi: 10.1016/j.quaint.2005.12.015

KLEESMENT, A. (2009): Roundness and surface features of quartz grains in Middle Devonian deposits of the East Baltic and their palaeogeographical implications.Estonian Journal Earth Sciences, 58/1, 71-84. doi: 10.3176/earth.2009.1.07

KRINSLEY, D.H. (2011): Atlas of quartz sand surface textures.- Cambridge University Press, Cambridge, $91 \mathrm{p}$.

KRINSLEY, D.H. \& TAKAHASHI, T. (1962): Applications of electron microscopy to geology.- New York Academy Science Transactions, 25/1, 3-22. doi: 10.1111/j.2164-0947.1962.tb03509.x

LUO, H., WU, F., WANG, D., CHANG, J., BAO, H., XU, J. \& MA, A. (2015): Physical and mechanical properties of Malan loess at Zhaojiaan landslide area.- Journal Engineering Geology, 23/1, 44-51(in Chinese, with English Abstr.).

MA, J.X., CHEN, J., CUI, Z.J., ZHOU, W., LIU, C., GUO, P. \& SHI, Q. (2018): Sedimentary evidence of outburst deposits induced by the Diexi paleolandslide- dammed lake of the upper Minjiang River in China.- Quaternary International, 464, 460-481. doi: 10.1016/j.quaint.2017.09.022

MAHANEY, W.C. (1992): Quartz particle types in Chinese and European loesses.Naturwissenschaften, 79/6, p. 266. doi: 10.1007/BF01175391

MAHANEY, W.C. (2002): Atlas of Sand Grain Surface Textures and Applications.Oxford University Press, New York, $237 \mathrm{p}$.

MAHANEY, W.C. \& ANDRES, W. (1991): Glacially crushed quartz grains in loess as indicators of long-distance transport from major European ice centers during the Pleistocene.- Boreas, 20/3, 179-192. doi: 10.1111/j.1502-3885.1991.tb00153.x

MAHANEY, W.C. \& ANDRES, W. (1996): Scanning electron microscopy of quartz sand from the north-central Saharan desert of Algeria.- Zeitschrift Geomorphologie N.F., Supplement-Bd, 103, 179-192.

MAHANEY, W.C. \& KALM, V. (1995): Scanning electron microscopy of Pleistocene tills in Estonia.- Boreas, 24/1, 13-29. doi: 10.1111/j.1502-3885.1995.tb00624.x

MAHANEY, W.C. \& KALM, V. (2000): Comparative scanning electron microscopy study of oriented till blocks, glacial grains and Devonian sands in Estonia and Latvia.- Boreas, 29/1, 35-51. doi: 10.1111/j.1502-3885.2000.tb01199.x

MAHANEY, W.C., CLARIDGE, C. \& CAMPBELL, I. (1996): Microtextures on quartz grains in tills from Antarctica.- Palaeogeography, Palaeoclimatology, Palaeoecology, 121/1, 89-103. doi: 10.1016/0031-0182(95)00069-0

MAHANEY, W.C., STEWART, A. \& KALM, V. (2001): Quantification of SEM microtextures useful in sedimentary environmental discrimination.- Boreas, 30, 165-171. doi: 10.1111/j.1502-3885.2001.tb01220.x

MAHANEY, W.C., VORTISCH, W. \& JULIG, P., (1988): Relative differences between glacially crushed quartz transported by mountain and continental ice: some examples from North America and East Africa.- American Journal Science, 288/8, 810-826. doi: 10.2475/ajs.288.8.810

MOLEN, M.O. (2014): A simple method to classify diamicts by scanning electron microscope from surface microtextures.- Sedimentology, 61/7, 2020-2041. doi: 10.1111/sed.12127

PETERKNECHT, K.M. \& TIETZ, G.F. (2011): Chattermark Trails: Surface Features on Detrital Quartz Grains Indicative of a Tropical Climate.- Journal Sedimentary Research, 81/1-2, 153-158.

PYE, K. (1983): Grain surface textures and carbonate content of late Pleistocene loess from West Germany and Poland.- Journal Sedimentary Petrology, 53/3, 973-980.

SMALLEY, I.J. \& GLENDINNING, S. (1991): Two distinct particle types in the Lanzhou Loess.- Naturwissenchaften, 78/4, p. 167. doi: 10.1007/BF01136203

STUUT, J.W., TEMMESFELD, F. \& DECKKER, P.D. (2014): A 550 ka record of aeolian activity near North West Cape, Australia: inferences from grain-size distributions and bulk chemistry of SE Indian Ocean deep-sea sediments.- Quaternary Science Reviews, 83/1-2, 83-94. doi: 10.1016/j.quascirev.2013.11.003

VOS, K., VANDENBERGHE, N. \& ELSEN, J. (2014): Surface textural analysis of quartz grains by scanning electron microscopy (SEM): From sample preparation to environmental interpretation.- Earth-Science Reviews, 128/1, 93-104. doi: 10.1016/j.earscirev.2013.10.013

WHALLEY, W.B. \& KRINSLEY, D.H. (1974): A scanning electron microscope study of surface textures of quartz grains from glacial environments.- Sedimentology, 21/1, 87-105. doi: 10.1111/j.1365-3091.1974.tb01783.x 

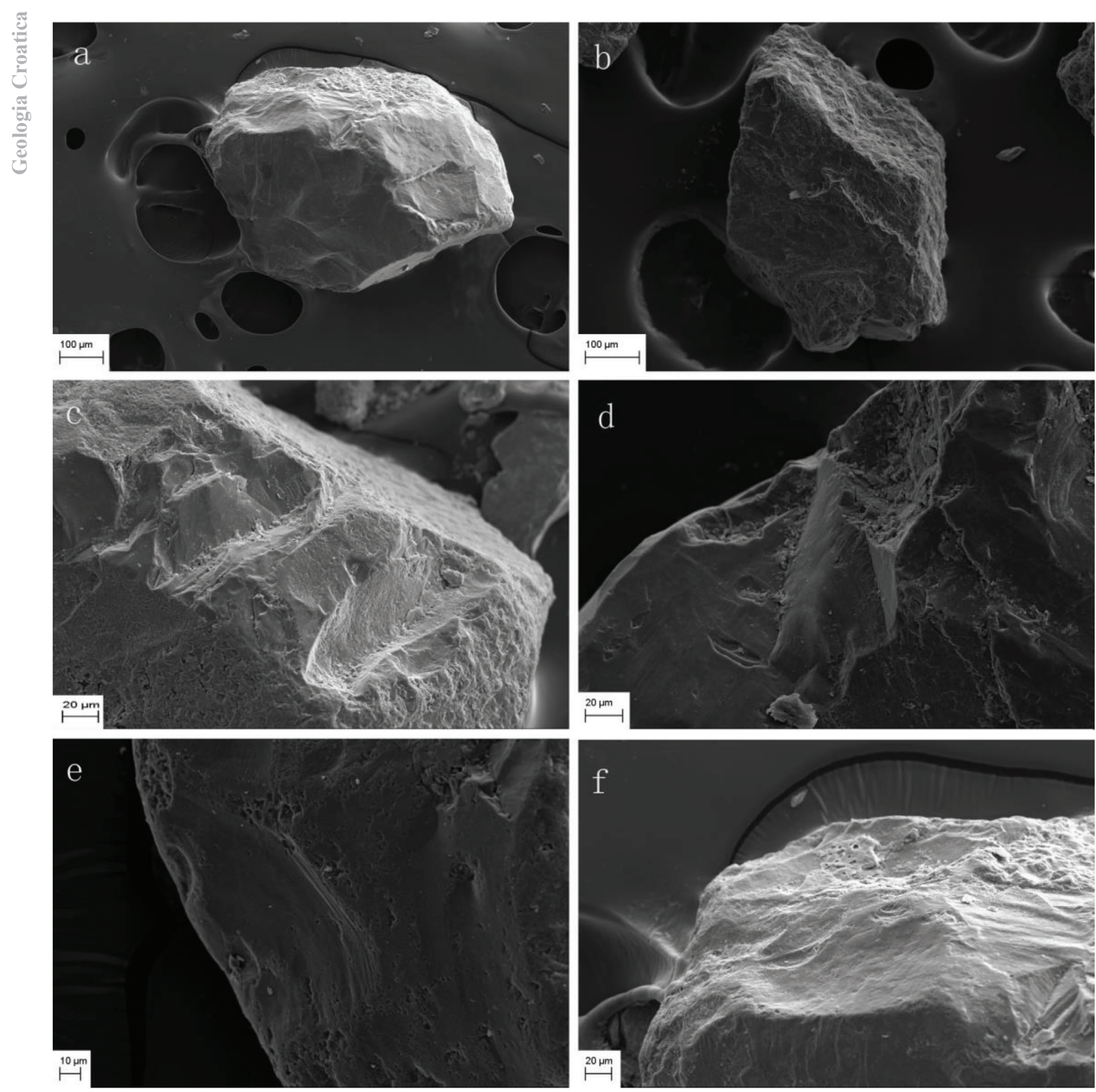

Plate 1 Photomicrographs of the quartz grains.

a - Sub-angular grains with V-shaped percussion cracks (upstream sediment)

b - Sub-angular grains with impact pits (upstream sediment)

c - Photomicrograph of a V-shaped percussion crack with adhering particles (downstream sediment)

d - V-shaped percussion cracks with residual conchoidal fractures at the top-right corners (downstream sediment)

e - Disc concave pit (downstream sediment)

f - Disc concave pit with a V-shaped pit at the bottom right corner (downstream sediment) 

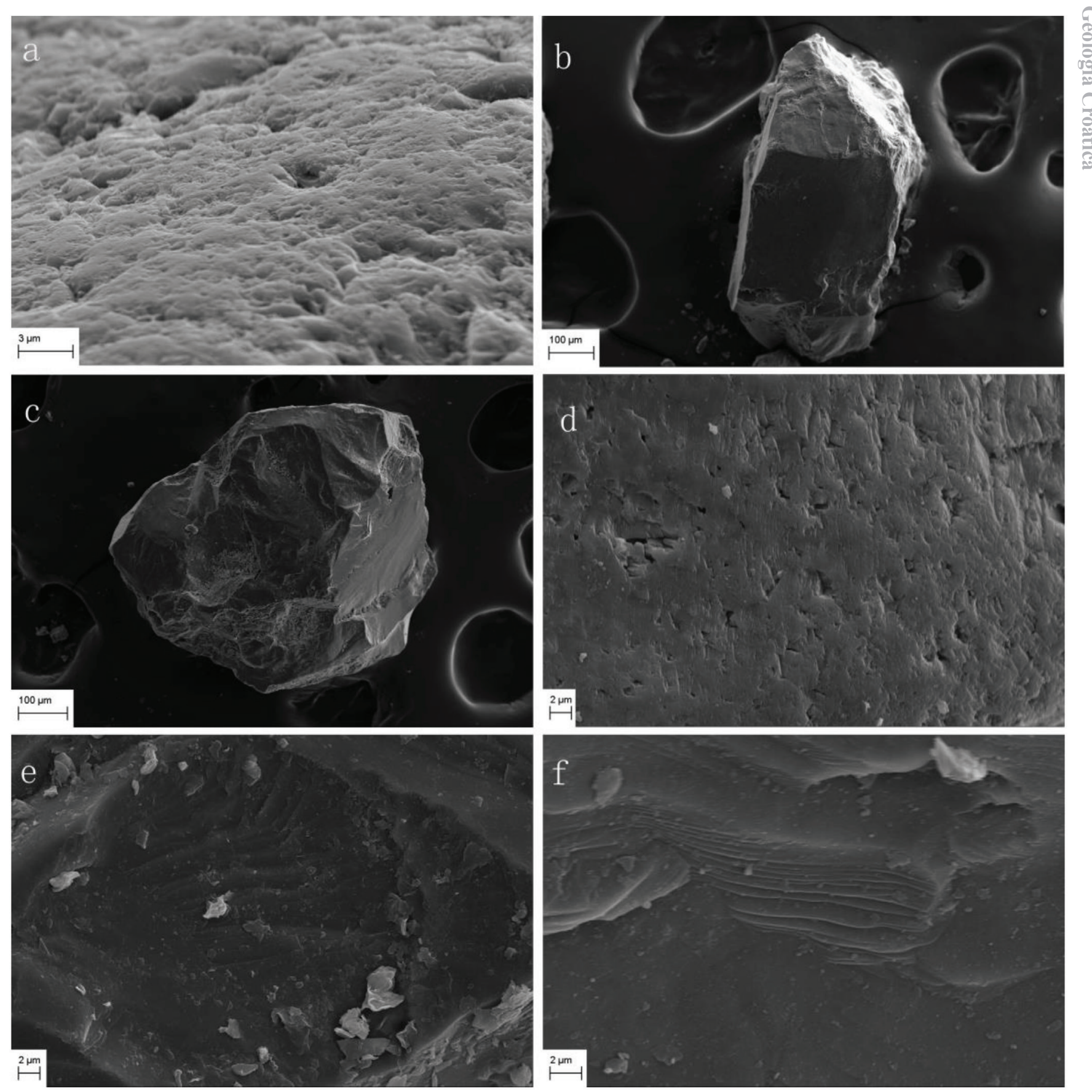

Plate 2. Photomicrographs of the quartz grains.

a - Solution crevasses at different scales (downstream sediment)

b - Sub-angular grains with underwater polished surfaces (downstream sediment)

c - Sub-angular grains with vague impact marks (upstream sediment)

d - Photomicrograph of chatter marks (downstream sediment)

e - Photomicrograph of adhering particles on the striations (midstream sediment)

f - Photomicrograph of adhering particles on the straight steps (downstream sediment) 